\title{
A Clinical Trial of Translation of Evidence Based Interventions to Mobile Tablets and Illness Specific Internet Sites
}

Carol E Smith ${ }^{1,2}$, Ubolrat Piamjariyakul ${ }^{1 *}$, Marilyn Werkowitch ${ }^{1}$, Donna Macan Yadrich ${ }^{1}$, Noreen Thompson ${ }^{1}$, Dedrick Hooper $^{3}$ and Eve-Lynn Nelson ${ }^{3-5}$

${ }^{1}$ School of Nursing, University of Kansas Medical Center, USA

${ }^{2}$ School of Preventive Medicine and Public Health, University of Kansas Medical Center, USA

${ }^{3}$ Center for Telemedicine and Telehealth, University of Kansas Medical Center, USA

${ }^{4}$ Pediatrics and Telemedicine, University of Kansas Medical Center, USA

${ }^{5}$ Institute for Community Engagement, University of Kansas Medical Center, USA

\begin{abstract}
This article describes a method to translate an evidence based health care intervention to the mobile environment. This translation assisted patient participants to: avoid life threatening infections; monitor emotions and fatigue; keep involved in healthy activities. The mobile technology also decreased costs by reducing for example travel to visit health care providers. Testing of this translation method and its use by comparison groups of patients adds to the knowledge base for assessing technology for its impact on health outcome measures. The challenges and workflow of designing materials for the mobile format are described.

Transitioning clinical trial verified interventions, previously provided in person to patients, onto tablet and internet platforms is an important process that must be evaluated. In this study, our evidence based guide's intravenous (IV) homeCare interventions (IVhomeCare) were delivered via Apple iPad mini ${ }^{\mathrm{TM}}$ tablet audiovisual instruction / discussion sessions and on a website. Each iPad audiovisual session $(n=41)$, included three to five families, a mental health specialist, and healthcare professionals. Patients and their family caregivers readily learned to use the wireless mobile tablets, and the IVhomeCare interventions, as described here, were successfully translated onto these mobile technology platforms. Using Likert scale responses on a questionnaire $(1=$ not helpful and $5=$ very helpful $)$ participants indicated that they gained problem solving skills for home care through iPad group discussion $(M=4.60, S D=0.60)$. The firewall protected videoconferencing in real time with multiple healthcare professionals effectively allowed health history taking and visual inspection of the patient's IV insertion site for signs of infection. Supportive interactions with peer families on videoconferencing were documented during discussions. Discussion topics included low moods, fatigue, infection worry, how to maintain independence, and need for support from others with their same lifelong IV experiences. The visual family interactions, discussions with professionals, and the iPad internet links were highly rated. Mobile distance care delivery can result in saved time and money for both healthcare professionals and families.
\end{abstract}

Keywords: Mobile technology; Intravenous catheter care; Group sessions; Translating to iPad and internet platforms

\section{Background and Significance}

Patients depending on daily intravenous (IV) catheter home care have a complicated medical regimen requiring significant time, energy, and resources [1]. These families have ongoing fears about risks of infection, hospitalization, and deteriorating health and function, as well as worries about finances and coverage to meet health care needs [2-4]. It is often challenging for patients and family caregivers to understand and adhere to the twice daily, multi-step IV therapy procedures $[5,6]$. Stresses associated with the regimen and the day-to-day demands of employment and family life place pressure on family members who may neglect their own physical and mental health. Notably, we have developed and validated a series of interventions that have reduce patients' IV infections, depression and fatigue and improve their families access to information and illustrations of homecare problem solving and healthy living activities [7-10]. The interventions include: infection, depression, and fatigue prevention; problem solving IVhomeCare with health professionals; and maintaining family health $[11,12]$. These and other interventions have previously been delivered in person, by telephone, and over internet [13-15].

\section{Related Work}

In previously validated interventions, patients and family caregivers managing complex and lifelong daily IV homecare needs have responded well to having access to visual instructions [16,17]. Support from peers, reinforcement of healthy living activities, and illustrated stepby-step guides improved safety and increased adherence to complex care at home [18]. Annual re-hospitalizations of patients on IVs result from complications that could be reduced using our research based interventions [19]. Specific IV homecare interventions (IVhomeCare) can be used daily by patients in their homes with professionals providing directions and clarifying IV procedures [20]. Professionals can also reinforce adherence to daily IV aseptic care routines that can reduce catheter infections and complications [21]. We have previously published, and other research has replicated our results indicating that our IVhomeCare interventions for infection prevention and mood and emotion monitoring have resulted in reducing incidents of IV catheter infections and decreasing clinically significant depression [22-24]. Also our intervention for problem solving partnerships with healthcare

*Corresponding author: Ubolrat Piamjariyakul, School of Nursing, University of Kansas Medical Center, USA, Tel: 19135881619; E-mail: upiamjariyakul@kumc.edu

Received February 15, 2016; Accepted March 08, 2016; Published March 15, 2016

Citation: Smith CE, Piamjariyakul U, Werkowitch M, Yadrich DM, Thompson N, et al. (2016) A Clinical Trial of Translation of Evidence Based Interventions to Mobile Tablets and Illness Specific Internet Sites. Sensor Netw Data Commun 5: 138. doi:10.4172/2090-4886.1000138

Copyright: $\odot 2016$ Smith CE, et al. This is an open-access article distributed under the terms of the Creative Commons Attribution License, which permits unrestricted use, distribution, and reproduction in any medium, provided the original author and source are credited. 
professionals and for short daily restorative naps result in greater patient problem-solving skills, reduced daytime fatigue, and improved quality of life [20]. Overall, these interventions have been associated with family success stories and lower healthcare costs [25]. To build on these outcomes and enhance interactive communication, we translated these in-person interventions to mobile technology platforms (example: tablets) with asynchronous Internet-based components available 24/7.

A number of advantages have been suggested for increased interest in mobile technologies in health care, including fewer families having a landline telephone connection, increasing use of mobile devices rather than desk or laptop computers, near ubiquitous wireless coverage with standardized policies for data security, availability even when traveling and ease of use of mobile devices, and improved clarity and detail of visual images and video [26]. Our patient survey results overwhelmingly indicated interest in mobile technologies rather than landline phones or desktop computers [16,27]. The Pew Research Center survey found that $72 \%$ of adults in the U.S. reported they seek information, care, or support from a healthcare professional via the Internet $[28,29]$. Thus, based on this patient and family input and with our focus on further extending our family-centered approach and meeting patient needs in the home, we translated our previously validated interventions onto mobile technology (i.e., Apple iPad mini ${ }^{\mathrm{TM}}$ tablets). The figure and tables herein describe the translated interventions and illustrate the work flow related to uploading and delivering the important information via mobile devise.

Using tablets equipped with secure encryption-based videoconferencing, patients and their family members / caregivers reliably connected are from their homes to healthcare professionals in their offices $[30,31]$. Further, the videoconference discussion sessions allowed the families and the professionals to interact with one another in real-time [32]. These telehealth technologies can be used to engage families in evidence-based interventions for IV catheter care, thus reducing care burden in home settings [33-35]. Our IVhomeCare interventions both provide peer support and address families who lack access to healthcare professional guidance and information about serious but preventable IV problems at home [36].

\section{Objectives}

The objectives of this study were to: (1) Translate IVhomeCare and healthy living interventions and deliver these via synchronous videoconferencing family group sessions through mobile tablets. (2) Offer IVhomeCare information via asynchronous Internet available 24/7. (3) Summarize the patient and family evaluations of the videoconferencing sessions with health professionals and other patients.

\section{Methods}

The university medical center's Institutional Review Board (IRB) approved the study procedures, following all IRB data management policies and Health Insurance Portability and Accountability Act (HIPAA) regulations for the iPad group intervention sessions and data collection. All participating patients and caregivers provided informed consent. Our clinical trial compared IV patients randomly assigned to either (1) the iPad comparison attention placebo group (without iPad appointments or our Internet site access) or (2) the experimental group who had iPad appointments and who were also provided with a translated mobile access interventions via iPad. Following the study, the comparison placebo group patients / family members were given the Internet access and one clinic appointment with professionals to evaluate. Patients and family caregivers who attended the group discussion sessions via the iPad mini were invited to evaluate the program.

The methods for translating the evidence-based IVhomeCare intervention components included: (1) delivering synchronous group videoconferencing sessions via the tablets; and (2) uploading the asynchronous IVhomeCare interventions (written information, forms, illustrations and graphics) to the mobile device Internet links. These two intervention approaches provided information and professional guidance to promote and support independent selfmanagement for complex IV infusion care at home and to provide evidence-based information available 24/7. The audiovisual group discussion among peers and professionals was conducted on encrypted and firewall-protected videoconference software to ensure privacy and confidentiality. The technology used to deliver the intervention components is a wireless mobile tablet (iPad mini) with unlimited $4 \mathrm{G}$ data plan, which was loaned to each family at no cost.

All tablets were put in hard cover stands that not only protected the tablet, but also allowed the tablets to be placed on tables or other surfaces rather than users holding them. This eliminated the iPad pixel blur during the video sessions, which sometimes results in unclear video. The tablet, power supply, and hard cover stand were all shipped to the user in a Fed Ex tablet box, along with a how-to use guide and shipping instructions on how to return the tablet to the System Coordinator at no cost to the user.

Our procedures were developed to give the end user (study participant) a secure, high quality, and user-friendly videoconferencing experience. While security and high quality are critical components, the ease-of-use is equally important to ensure user satisfaction and increase success of the project.

\section{Delivering the synchronous videoconferencing sessions}

Tablets offer visual patient monitoring by healthcare professionals, allowing early detection to avoid IV sepsis. Such visual monitoring can prevent the frequent emergency room visits or hospitalizations that may result when early signs of problems are missed with non-visual telephone calls. Mobile connections have the added advantage of not exposing patients to infection risks from hospitals or clinic visits; as this group of patients is especially vulnerable to bloodstream infections [37].

Each imaged iPad tablet with the transferred intervention materials was listed in our study record for tracking purposes. Recorded log data included the assigned tablet name, serial number (SN), Mobile Equipment Identifier (MEID), Integrated Circuit Card Number (ICCID), and Cellular Data Number. The iCloud username and password were also recorded in case the tablet needed to be disabled, if lost or stolen. Upon return, the Systems Coordinator noted the study log of its successful return as well as assessed the tablet, power cord, and hardcover stand for any damage. The coordinator also disinfected the tablet using the cleaning protocols established by Apple. After completing updates, the Systems Coordinator recorded any applications installed to tablets by the user into the study log and then deleted all data by selecting "Erase all Content and Settings" on the tablet.

\section{Communications technology}

Our Network engineer and system coordinator developed an approach for setting up each iPad prior to giving to the end user (our study participant patient) and once the iPad was returned from 
Citation: Smith CE, Piamjariyakul U, Werkowitch M, Yadrich DM, Thompson N, et al. (2016) A Clinical Trail of Translation of Evidence Based Interventions to Mobile Tablets and IIIness Specific Internet Sites. Sensor Netw Data Commun 5: 138. doi:10.4172/2090-4886.1000138

the patient the medical center and apple directions (Figure 1). The Polycom $^{\text {Tu }}$ RealPresence software was pre-loaded on tablet devices using all best practices for HIPAA-compliant, encrypted audio-visual delivery in order to securely connect to the videoconferencing sessions omg. With the participants' full knowledge and consent, the sessions were videotaped for later review. Families were not required to have previous experience using the iPad mini. An iPad user help guide was uploaded onto each iPad mini, and a printed copy was also shipped to homes along with the iPad. In addition, our telehealth systems coordinator was available by phone to support families' iPad usage.

Our project allowed users to connect via videoconference to a fully encrypted Multipoint Conferencing Unit (MCU). This was accomplished by allowing an iPad to become an endpoint that is internal to the University of Kansas Medical Center (KUMC) network. This network resides behind a firewall for privacy. The Polycom RealPresence mobile application, also called the Polycom app, was available at no cost via the Apple app store, and was loaded on to the iPads. The KUMC Network Engineer created a unique username and password for each individual tablet. The flowchart in Table 1 details each of these activities followed for managing the iPad technology that allowed the tablets access to the KUMC network via its external Video Border Proxy (VBP). The VBP was purchased for the study to provide encryption to video devices external to the KUMC network. The VBP was given a URL registration point to which external units registered. It was only when the Polycom app was registered to the VBP that the conference was encrypted. Therefore, the Systems Coordinator set the Polycom app to auto-register every time it was opened, saving the users (our study participant patients) the burden of registering each time. The VBP also allowed the user access to the application's "Directory," which the technician used to store the dial-in information in order to connect to the MCU. The user would simply open the Polycom app, access the Directory, and call the only entry available (Figure 1). During the study our coordinator was contacted by one-third of the patients, all of whom wanted practice in connecting and using the $\mathrm{iPad}$ within a week of receiving it. The remaining patients connected per our graphic instructions.

Scheduling and establishing the connection: The iPad mobile group sessions consisted of pre-scheduled iPad videoconferencing appointments with patients and their family members and healthcare professionals. Prior to the session, the coordinator completed test connections with each family resolve any connection problems or difficulties with adequate lighting. On the day of the session, the IT expert connected all families with the health professional interventionists. All participants appeared on screen in small separate picture tiles so that all were able to view each other and the facilitators on the tablet screen.

iPad session training and procedures: Before beginning the intervention, the professionals were trained as facilitators to: (1) maintain the communication to ensure participation and confidentiality; (2) focus the discussion to identify patient-centered problems and concerns; (3) enhance problem-solving partnerships with health professionals; (4) encourage families to share their experiences and offer one another support; (5) clarify misinformation shared by families; and (6) encourage families to discuss questions and concerns with their primary healthcare providers.

Mobile group sessions: Sessions were facilitated by an interventionist with extensive IV homecare experience and a mental health clinical specialist. This specialist both facilitated the discussion and addressed the depression often found among these homes bound

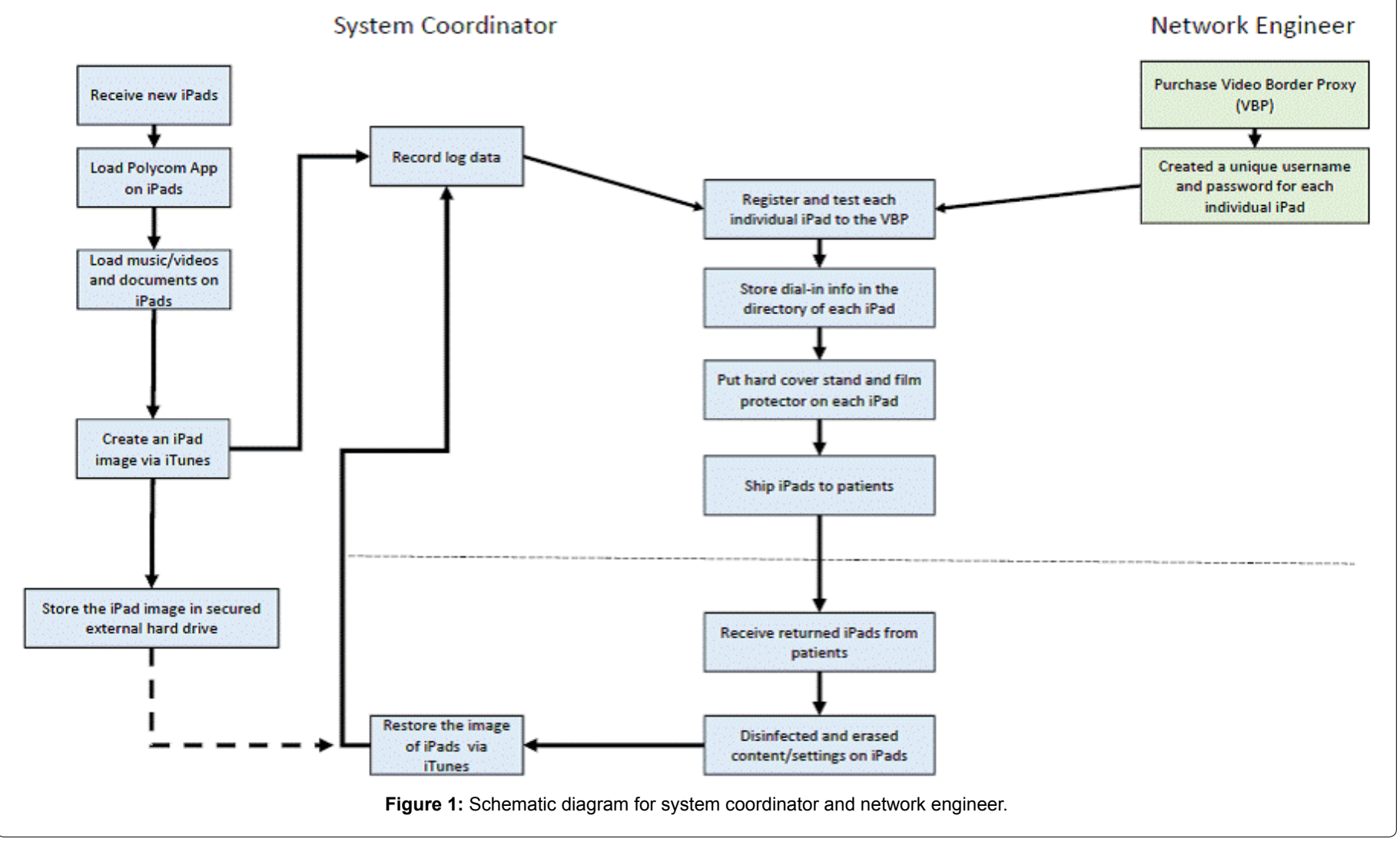


Flow chart for uploading and delivering the translated intervention content via iPad

KUMC Network Engineer created a unique username and password for each individual tablet. This allowed the tablet to access the KUMC network via its external Video Border Proxy (VBP). The VBP was purchased for the study in order to provide encryption to video devices external to the KUMC network.

After received new iPads, System Coordinator used two iPads to create templates for the two research groups: "intervention" and "control". All educational documents were created in HTML format and placed on KUMC web server. Music files and training videos were loaded on iPads. On the iPad homepage, these HTML documents were grouped and named "HPN Resources" in a folder, which allowed study participants to access these documents.

System Coordinator also loaded the Polycom App on iPads, via a free Real Presence app from the Apple App store, and recorded log data:

1. Assigned tablet name

2. Serial Number (SN)

3. Mobile Equipment Identifier (MEID)

4. Integrated Circuit Card Number (ICCID)

5. Cellular Data Number

6. iCloud username and password

The two iPads were loaded with different resources for "intervention" and "control" groups. Next they were created with different iPad images via iTunes. Both image files were stored in the secure external hard drive for restoring iPads later.

System Coordinator restored the images via iTunes on new iPads for new study participants.

System Coordinator registered and tested each individual iPad to the VBP. He set the app to auto-register every time the Polycom application was opened, thus saving the user the burden of registering each time. The VBP also allowed the user access to the application's "Directory," which the coordinator used to store the dial in information in order to connect to the MCU (Multipoint Conferencing Unit). The user could then easily open the app, access the Directory, and call the only entry.

System Coordinator put hard cover stand and film protector on iPads and shipped to users / study participants.

Upon return, the System Coordinator noted the study log, assessed the iPad for any damage. System Coordinator disinfected and erased all contents and settings on iPads. Restored images again and sent to the next user / study participant.

Table 1: Flow chart of detailed intervention activities.

IV patients. The mobile group session began with introductions, establishing a welcoming group environment focused on mutual respect. The facilitators then delivered self-management information for the IVhomeCare intervention and facilitated the group discussion. Sessions were scheduled for up to 90 minutes, with the average session lasting 56 minutes. The multiple patients and family members / caregivers engaged in discussions, shared experiences, and offered peer support to each other.

The IVhomeCare intervention included two scheduled mobile group sessions with multidisciplinary healthcare professionals in their office and three to five families in their own homes. A family included the patient and at least one family member or other caregiver. The number of participants in these sessions ranged from four to nine depending on the numbers of family members. In each mobile group session, the facilitators: (1) introduced the participants and themselves and reviewed related HIPAA regulations asking group members to keep information shared confidential; (2) explained session ground rules (similar to other support groups), including using first name only and sharing only what one wants others to know; (3) reminded individuals that the facilitators and other group members are not providing medical advice nor endorsing any specific IV products; and (4) encouraged use of the iPad mini Internet links to IVhomeCare resources on our website [38].

Session content focused on our empirically supported IVhomeCare interventions and the asynchronous components of these interventions: Infection prevention monitoring intervention; Mood and emotion monitoring intervention; Problem-solving partnership intervention; Fatigue monitoring and restorative nap intervention; Family healthy living activities intervention; and Daily self-monitoring and early reporting using checklist. Details of their IV homecare concerns and use of the iPad to link to health professionals and to the IVhomeCare intervention website information closed the discussion.

The facilitators provided guidance if the group reached an impasse and corrected misinformation. The facilitators strove to refrain from lecturing, and they promoted nonjudgmental information sharing. As a follow-up to these interventions, online automated text message prompts were sent via an encrypted email account (restrictively used for this study) to each family member through the iPad mini. The prompts were used to reinforce intentions to use the IVhomeCare interventions.

Because families managing lifelong IVs at home rarely meet others in similar situations, peer support was an essential component of the group sessions. Social isolation is common in this population due to patients frequently being homebound and having limited time to socialize given their daily IV treatments [39]. Our iPad mobile sessions with multiple families decreased social isolation by allowing families to share their stories and support one another around home IV care issues [40]. In addition, a majority of adults reported that it was beneficial to interact with others who have the same healthcare concerns. Such interaction with peer patient groups and their families' help patients learn "how to cope with a health issue or get quick relief." However, they turned to healthcare professionals when they needed specific advice for complex homecare.

\section{Translating the asynchronous IVhomeCare interventions to the iPad tablets}

New opportunities and challenges arise when translating previously validated interventions to the mobile environment, necessitating attention to maximize the benefit of the new technology [41,42]. Table 2 summarizes the IVhomeCare interventions and describes considerations for translating them for mobile delivery, including access to Internet platforms.

Internet resources: The iPad mini tablets were pre-loaded with previously validated IVhomeCare Resources website links, to provide the benefit of Internet access at any time that meets patient and family needs. The IVhomeCare intervention website provides: evidencebased symptom monitoring algorithms; IVhomeCare illustrations and step-by-step support for independent homecare management; and problem-solving partnership guides with healthcare professionals [43].

Families readily learned to use the iPad mini's interactive touchscreen features that provide a fast and easy way for families to access the IVhomeCare interventions [44]. The IVhomeCare Resources icon on the iPad mini home-screen connects directly to the IVhomeCare intervention website links, and the individual intervention webpages are available $24 / 7$ for quick reference of a specific topic (Table 3). The IVhomeCare Resources icon also connects to digital versions of 
Citation: Smith CE, Piamjariyakul U, Werkowitch M, Yadrich DM, Thompson N, et al. (2016) A Clinical Trail of Translation of Evidence Based Interventions to Mobile Tablets and IIIness Specific Internet Sites. Sensor Netw Data Commun 5: 138. doi:10.4172/2090-4886.1000138

Page 5 of 11

\begin{tabular}{|c|c|c|}
\hline Intervention Name & $\begin{array}{l}\text { Description of IV Home Care } \\
\text { Intervention Content }\end{array}$ & $\begin{array}{l}\text { Advantages / Challenges to Translating the } \\
\text { IV Home Care Information into the Mobile } \\
\text { Environment }\end{array}$ \\
\hline $\begin{array}{c}\text { Internet Links to IV home } \\
\text { Care Resources }\end{array}$ & $\begin{array}{l}\text { - Scientifically based algorithms guide families through specific } \\
\text { management and reporting of the } 42 \text { most common IV } \\
\text { homecare problems. } \\
\text { - Internet website links with online access provide information } \\
\text { in one place and allow continuously updated information, } \\
\text { compared with static paper versions: } \\
\text { o Oley Foundation Lifeline Newsletter for alerts and information } \\
\text { about IV home care. } \\
\text { o Caregiving advocacy resources, such as National Caregiving } \\
\text { Alliance and other caregiver advocacy. } \\
\text { o Bilingual and other website links. } \\
\text { - Guide on how to determine quality of information. }\end{array}$ & $\begin{array}{l}\text { - Internet web links easily pre-loaded on the iPad and materials readily } \\
\text { accessible to patients and their family members. } \\
\text { - Support group participants reinforced use of the Oley Foundation } \\
\text { resources, noting which resources were particularly beneficial in } \\
\text { their own lives and sharing experience posting questions on the Oley } \\
\text { Foundation social media resources. }\end{array}$ \\
\hline $\begin{array}{l}\text { Infection Prevention } \\
\text { Monitoring }\end{array}$ & $\begin{array}{l}\text { - Audiovisual scenarios illustrate: } \\
\text { o Hand washing techniques. } \\
\text { o Maintenance of equipment and storage area. } \\
\text { o Care of the IV catheter insertion site. } \\
\text { - A music jingle that times hand washing for } 1 \text { minute (per CDC } \\
\text { guidelines). } \\
\text { - Self-monitoring checklist guides patients to follow a daily } \\
\text { routine for self-monitoring IV care (Table } 4 \text { ). } \\
\text { - Interactive digital game guides identification of infection } \\
\text { symptoms. }\end{array}$ & $\begin{array}{l}\text { Mobile device provides ease of access and repeated viewing, even } \\
\text { when the patient is outside the home setting. } \\
\text { - Pre-loaded photographs show possible arrangements for the large } \\
\text { volume of storage of sterile equipment and supplies, a major issue. } \\
\text { - Music guiding hand washing is available on the touch-screen. } \\
\text { - Future updates will allow the procedure checklist to be in a "fill-in form" } \\
\text { - Support group participants supported one another in applying the } \\
\text { scenarios to their daily life. }\end{array}$ \\
\hline $\begin{array}{l}\text { Mood and Emotion } \\
\text { Monitoring }\end{array}$ & $\begin{array}{l}\text { Journal writing about low moods (Table 5). } \\
\text { o Mudiovisual scenes illustrate: } \\
\text { o Self-monitoring checklist that encourages monitoring mood } \\
\text { by: } \\
\text { - A } 10 \text {-item scale for rating daily mood / emotional reactions } \\
\text { [11] (Table 4). } \\
\text { - Engaging in mood elevating activity (Table 4). } \\
\text { - Interactive digital game guides confidence building for } \\
\text { positive outlook. }\end{array}$ & $\begin{array}{l}\text { - New options are available for online journal writing in order to easily } \\
\text { access the journal, avoiding risks of paper documentation (e.g., loss or } \\
\text { damage to the paper version, less privacy). } \\
\text { - Online tools allow increased options for patients to track their progress } \\
\text { graphically and note changes over time. } \\
\text { - Future online checklist options will include searchable forms and } \\
\text { associated alerts to the patient / family / provider should depression } \\
\text { warning signs arise. } \\
\text { - Support group participants provided real-life examples of mood- } \\
\text { elevating activities, ranging from knitting to participating in car shows. } \\
\text { - Support group participants provided positive reinforcement to other } \\
\text { participants as well as normalizing experiences, all of which are } \\
\text { associated with mood enhancement. }\end{array}$ \\
\hline $\begin{array}{l}\text { Problem-Solving } \\
\text { Partnership }\end{array}$ & $\begin{array}{l}\text { Audiovisual scenes illustrating problem-solving with } \\
\text { healthcare professionals. } \\
\text { Scientifically based algorithms with step-by-step guides for } \\
\text { solutions to the most common IV problems. } \\
\text { - Prompts for establishing an IV home care routine. } \\
\text { Prompts for working with healthcare providers and insurers to } \\
\text { address problems. }\end{array}$ & $\begin{array}{l}\text { Mobile access facilitates use of problem-solving resources, particularly } \\
\text { at times when the patient / family are under additional stress and can } \\
\text { benefit from such strategies. } \\
\text { The digital space for saving screens is greatly enhanced on the tablet } \\
\text { format. } \\
\text { problem-solving steps, such as how to request delivery of needed } \\
\text { infection control supplies to an upper-level apartment when one is at } \\
\text { work. }\end{array}$ \\
\hline $\begin{array}{l}\text { Fatigue Monitoring and } \\
\text { Restorative Nap }\end{array}$ & $\begin{array}{l}\text { Fatigue monitoring sheets are provided. } \\
\text { Science-based information indicating short naps improve } \\
\text { attention to detail. } \\
\text { A music-guided restorative daytime nap. }\end{array}$ & $\begin{array}{l}\text { Fatigue monitoring forms are more readily accessible with mobile tools. } \\
\text { Tablets allow various types of music (soft rock, classical, etc.) and } \\
\text { ease of use with the ability to take the mobile device anywhere in one's } \\
\text { home or outside the home when on vacation, etc. } \\
\text { - Support group participants shared times that they had tried the } \\
\text { restorative nap and problem solved barriers to such naps together. }\end{array}$ \\
\hline $\begin{array}{l}\text { Family Healthy Living } \\
\text { Activities }\end{array}$ & $\begin{array}{l}\text { - Illustration of health promotion and healthy living activities: } \\
\text { o Simple daily walking exercise. } \\
\text { o Lower sugar and salt intake and healthy eating. }\end{array}$ & $\begin{array}{l}\text { - The synchronous session allowed the facilitators to reinforce that } \\
\text { information on healthy activities varies with patients and family } \\
\text { caregivers need clarification. Also, realistic limits on suggested } \\
\text { activities can be discussed, improving intentions for participation. }\end{array}$ \\
\hline $\begin{array}{c}\text { Group Discussions and } \\
\text { Peer Support }\end{array}$ & $\begin{array}{l}\text { - Exemplar peer and family stories shared through the web } \\
\text { resources. } \\
\text { - Support gained from other families experiences about } \\
\text { managing IV home care. } \\
\text { - Group discussions conducted after each IV Home Care } \\
\text { intervention session. }\end{array}$ & $\begin{array}{l}\text { - Increased group discussion and peer support through the mobile } \\
\text { videoconferencing sessions, with social support and encouragement or } \\
\text { preventing feelings of isolation when homebound. }\end{array}$ \\
\hline
\end{tabular}

Table 2: Comparison of traditional IV home care in-person content and translation of this content into interventions for the mobile environment.

the IVhomeCare intervention information about: (1) monitoring for infection prevention; (2) monitoring mood and emotions; (3) supporting problem-solving partnerships with healthcare professionals; (4) monitoring fatigue and providing a restorative nap guide to reduce daytime fatigue; and (5) sharing healthy living activities including daily exercise and physician recommended sugar / salt intake. This information is described in more detail below.
The IVhomeCare website incorporates the National Institutes of Health (NIH) Web Literacy and National Disabilities Act standards including large-font text, simple graphics, and easy-to-locate, straightforward navigation symbols [46,47]. This website provides IVhomeCare guidance and illustrated instructions that encourage the patient and family members to use the information in daily IVhomeCare routines. In addition, the IVhomeCare Resources includes a list of 
Infection Prevention. Video scenarios depict hand washing techniques using our prescribed timed music jingle and checklist guides for infection control. The interactive digital game Improving Sepsis Recognition and Management through a Mobile Education Game, a case-based interactive learning using a set of typical infection cases that follow evidence-based treatment algorithms. Players make decisions about reporting symptoms and watch as the case condition changes. The game's rapid pace underscores the importance of daily temperature taking, IV site assessment, and early symptom reporting. Points are awarded for correctly managing and answering questions.

Depression Prevention. Based on Depression Awareness and Management, (National Institutes of Health, U.S. Department of Health and Human Services) depression prevention includes mood self-monitoring with relaxing music as well as video scenes that illustrate mood-elevating activities. This is a safe approach for IV patients who have limited oral intake, such that depression medications are not absorbed. Family members, also have reactive depression.

Problem-solving IV Care Partnerships. Video scenarios and specific algorithms for the 48 known frequently recurring IV homecare problems are based on national clinical guidelines and FDA updates and alerts. Prompts for working with healthcare professionals to address problems are sent via the iPad.

Power Nap. A short, effective music-guided 10-minute daytime restorative nap addresses fatigue. Short Daytime Restorative Naps [45] is guided by self-selected music (soft rock, slow hip-hop, classical, etc.); each selection initially reduces cadence and is shown to relax into REM sleep. An interactive game measures subjects' fatigue via reaction time (a measure of sleep deprivation).

Taking Care of You. Engagement in interactive healthy living activities is tracked using automated prompts. Motivating prompts are used in our KUMC employee healthy living "Stick-to-it-iveness" software. This program has successfully engaged 600 adults in long-term health activities.

Family Success Stories. Exemplar stories from experienced families about managing IV home care show challenges met. Each is reviewed by healthcare professionals and de-identified prior to placement online.

Scripted Guides. To promote comprehensive communication with their healthcare providers (MD and / or RN) or insurance providers, these guides assist and empower families.

Oley Foundation News. FDA alerts and important new IV catheter information is available from the national multidisciplinary family advocacy organization.

Resource Information - links to National Caregiving Alliance and other family caregiving resources.

Multilingual and Other Website Links. Easy-to-use Internet pages that provide automated language translation.

\section{Social Media and Games for families:}

Hand Hygiene https://itunes.apple.com/gb/app/hand-hygiene-training

- Breathe2Relax interactive app from Natl. Center for Telehealth with breathing skills for stressful situations. Includes video demo and charts for mapping use.

- SPARX is a digital game where the player creates an avatar that fights GNATs (Gloomy Negative Automatic Thoughts). The player participates in confidence-building skills to achieve a positive outlook, avoid depression, and seek help when needed.

- Social Media Safety Guide. The safety on social media intervention uses the "Be a Good Cyber Citizen Guide" developed by the National Crime Prevention Council. It includes criteria for determining the quality of web information per US Media Common Sense and the Cyber bullies Zombie games.

Table 3: IV Home care intervention website content and IV home care illustrated instructions.

frequently asked questions and answers, decision-making guides, and online health assessment tools using game formats with immediate feedback. The IVhomeCare self-monitoring checklist webpage is also available on the IVhomeCare website. Mobile group sessions reinforce the use of these online resources by families (Table 4).

\section{IVhome care interventions website}

On our intervention website, families have access to the Oley Foundation's (family advocacy association) Lifeline Newsletter for information about IV home-care and a scientifically developed IV catheter complication chart. Other links direct families to caregiving advocacy resources such as the National Caregiving Alliance and the Family Alliance for Caregiving. Our website also provides a guide to help determine the quality of the information found on websites [48].

Infection-prevention monitoring intervention: Patients with IV catheters need to adhere to strict aseptic techniques and IV procedures, and their family members need to learn the complex technological treatments that are required to avoid life-threatening IV catheter infections [49]. The infection prevention intervention of IVhomeCare consists of short video scenes: (1) demonstrating the proper technical procedures of hand washing, guided by a catchy jingle; (2) maintaining IVhomeCare equipment; (3) sanitizing the infusion area; and (4) practicing home asepsis for infection prevention.

The lyrics for the music jingle "All You Need for Good Hand washing: Water, Soap and Time" teach about removing jewelry, cleaning areas under nails, and vigorously scrubbing for the duration recommended by the Centers for Disease Control and Prevention (CDC). The music has repeating lyrics, which drastically improves memory and task attention and is similar to the large effect of mnemonic devices [45]. The short video scenes and hand washing song can easily be accessed from the bottom of the iPad home screen under the Video and Music icons. Music interventions have been associated with cognitive improvements and reduced distractibility, all important in IV catheter infection prevention [50].
The infection prevention intervention was extended by including the recommended updates for home care based on scientific guidelines from the CDC for IV device-related infection control in the home setting [51,52]. Thus, follow-up reminders and prompts for safe IV procedures can be readily communicated via the mobile technology (iPad mini)

Mood and emotion monitoring intervention: The magnitude of daily care and the patient's chronic illness may negatively impact the whole family and lead to episodes of depressive moods and emotional upset [53]. Situational or reactive depression is common in both IVhomeCare patients and their family members and may result from, for example, worrying about the patient's IV catheter infections or illness exacerbations and the financial strain of costly out-of-pocket healthcare expenses [54]. This may lead to emotional burnout and repeated episodes of depression.

Patient or family member depression can interfere with IV care because depression is characterized by the inability to: (1) concentrate during IV procedure training; (2) maintain IVhomeCare skills; or (3) make problem-solving decisions [55]. Patients and family members who are experiencing depressive symptoms have more difficulty adhering to aseptic techniques, resulting in a higher likelihood of unintentional touch contamination during IV catheter care [56]. Thus, our IVhomeCare intervention includes self-monitoring of mood and emotion. This intervention acknowledges that depressive episodes do occur and asks patients and family members to: (1) monitor their daily mood and common emotional reactions; (2) identify personal techniques that they have used to decrease situational depression; and (3) recognize early warning signs associated with major depressive disorders and share such symptoms with healthcare professionals. Specifically, a monitoring scale is provided for families to rate mood and engagement in mood-elevating activities [57].

Family members can use a page of the daily self-monitoring checklist to write about their emotions, problem-solving techniques, 
Citation: Smith CE, Piamjariyakul U, Werkowitch M, Yadrich DM, Thompson N, et al. (2016) A Clinical Trail of Translation of Evidence Based Interventions to Mobile Tablets and IIIness Specific Internet Sites. Sensor Netw Data Commun 5: 138. doi:10.4172/2090-4886.1000138

Page 7 of 11

\section{Care Daily Self-monitoring Checklist and Depression / Mood and Fatigue Monitoring Activities}

INSTRUCTIONS: Click on the actions below just before connecting or after disconnecting from the IV. Put a checkmark in the box on the days you monitor your own Infection Principles (hand washing, temperature check, safe procedures, and OBSERVING YOUR IV site). Emotions and Sleepiness ratings will lead you to determine your Depression / Mood and Fatigue Levels. We especially want you to do a mood-elevating activity any time you rate your mood at 5 or lower. One important activity for raising mood is writing about your feelings and emotions at least 3 times a week (make one of the days on the weekend). See Table 5. Use Problem-solving with health professionals when needed, and use the short naps to manage your fatigue.

\begin{tabular}{|c|c|c|c|c|c|c|c|}
\hline (:) HAND WASHING OF IV USER and FAMILY & Sun & Mon & Tue & Wed & Thu & Fri & Sat \\
\hline 1. Use soap and water. & & & & & & & \\
\hline 2. Scrub vigorously for at least 1 minute. Rinse and dry. & & & & & & & \\
\hline 3. Use a clean paper towel. & & & & & & & \\
\hline 4. Apply alcohol-based hand sanitizer. & & & & & & & \\
\hline (:) MONITOR TEMPERATURE OF IV USER & Sun & Mon & Tue & Wed & Thu & Fri & Sat \\
\hline $\begin{array}{l}\text { EXAMPLE: } \\
\text { 1. Report abnormal temperature ( }>\text { or }<\text { normal). }\end{array}$ & 96.8 & 97.0 & 98.8 & 99.0 & 99.4 & 99.8 & 100.4 \\
\hline 2. Report to MD / RN when chills occur. & & & & & & & \\
\hline 3. Monitor when patient doesn't feel well. & & & & & & & \\
\hline (:) SAFE WORK PROCEDURES FOR IV CARE & Sun & Mon & Tue & Wed & Thu & Fri & Sat \\
\hline 1. Check for expiration dates / sterile packages intact. & & & & & & & \\
\hline 2. Dispose of needles / syringes safely. & & & & & & & \\
\hline 3. Use friction with alcohol on hub connections. & & & & & & & \\
\hline (;) IV CATHETER INSERTION SITE. Check for: & Sun & Mon & Tue & Wed & Thu & Fri & Sat \\
\hline 1. Redness. & & & & & & & \\
\hline 2. Pain / tenderness. & & & & & & & \\
\hline 3. Swelling. & & & & & & & \\
\hline 4. Drainage. & & & & & & & \\
\hline (;) EMOTIONS and FATIGUE OF IV USER and FAMILY & Sun & Mon & Tue & Wed & Thu & Fri & Sat \\
\hline $\begin{array}{l}\text { 1. Rate your feelings of being sad, unhappy, depressed, gloomy, or discouraged. If rate is } \leq 5 \\
\text { write about your feelings on the back page. } \\
\begin{array}{ll}12345678 & 910 \\
\text { Worst Feelings } & \text { Best Feelings }\end{array}\end{array}$ & & & & & & & \\
\hline $\begin{array}{l}\text { 2. If rate is } \leq \mathbf{5} \text {, did you do an activity that you think is relaxing, enjoyable, and will help with a } \\
\text { positive outlook. Circle Yes }(\mathrm{Y}) \text { or No }(\mathrm{N}) \text {. }\end{array}$ & $\mathrm{Y} / \mathrm{N}$ & $\mathrm{Y} / \mathrm{N}$ & $\mathrm{Y} / \mathrm{N}$ & $\mathrm{Y} / \mathrm{N}$ & $\mathrm{Y} / \mathrm{N}$ & $\mathrm{Y} / \mathrm{N}$ & $\mathrm{Y} / \mathrm{N}$ \\
\hline $\begin{array}{l}\text { 3. Your dozing off or falling asleep: watching TV, sitting reading, while in a car or stopped for } \\
\text { traffic light. Use short nap music if }>\mathbf{2} \text {. } \\
0 \begin{array}{ccc}1 & 2 & 3\end{array} \\
\text { Never Slight Moderate High }\end{array}$ & & & & & & & \\
\hline (;) TRY THESE MOOD ELEVATING ACTIVITIES: & Sun & Mon & Tue & Wed & Thu & Fri & Sat \\
\hline Write the number of times each day you used: & & & & & & & \\
\hline 1. The checklist above. & & & & & & & \\
\hline 2. Soothing music, hugging, back or necks rub. & & & & & & & \\
\hline 3. Enjoyable activity (e.g. hobby, reading, phone calls). & & & & & & & \\
\hline 4. Talking to others (friends, family, peers, etc.). & & & & & & & \\
\hline 5. Short 10-minute nap. & & & & & & & \\
\hline 6. Use problem-solving with health professionals. & & & & & & & \\
\hline
\end{tabular}

Table 4: The IV home care self-monitoring checklist webpage.

and partnership with peer groups (Table 5). Journal writing about current mood and emotions has been shown to increase a positive outlook and may enhance the body's immune system to help avoid infections [58].

Problem-solving partnership intervention: The problem-solving approach is based on the American College of Physicians' Homecare Guide [59] and has been used in other clinical trials [60]. Patients are assisted in identifying their problems and potential solutions by partnering with healthcare professionals. Increased patient longevity and closer physician-patient relationships have been found when problem-solving partnerships were used [61]. The partnership for problem-solving processes can result in increasing patient symptom management and improving physical status, emotional health, and quality of life [62]. Problem-solving skills are practiced by families in each session and reinforced using the pre-loaded videos, the selfmonitoring checklist, and the group discussions. Patient concerns about IVhomeCare were facilitated during group discussions and problem-solving skills were reinforced.

Fatigue monitoring and restorative nap intervention: Fatigue management helps improve IVhomeCare because fatigue decreases concentration and increases the risk for poor health [45]. Patients and family members often experience fatigue due to the demands of daily, time-consuming IV infusion procedures. This includes adherence to strict aseptic techniques for hook-up and disconnect from the IV pump. Infusions are often completed over 12 hours, resulting in frequent night-time sleep interruptions, as well as interruptions from IV pump alarms and frequent bathroom trips [63,64]. The National Sleep Foundation (NSF) states that many people are alert in the morning and see a dip in alertness in afternoon. Thus, our IVhomeCare intervention provides a guide to a short da-time nap to help restore levels of energy to last through the evening. The nap music with focused imagery induces relaxation and is accompanied with softly spoken instructions 
INSTRUCTIONS: At least three times a week (use one weekend day), write about your use of Infection Prevention Principles, Emotions Monitoring, and Problem Solving and Partnering with others. Note any actions you took to improve your mood, as well as writing about IV homecare self-management problems / concerns and problem-solving techniques used.

\section{EXAMPLES:}

2 / 26 - Every Monday, Wednesday and Saturday morning, I check soap and other IV supplies. We called for new order so we don't run out on the weekend.

Also called the MD on Friday as 99.8 was 1 degree higher than usual. I'm worried an infection is coming on that is so frightening.

2 / 28 - The cat jumped on the counter while I was hooking up to the IV tubing. Fortunately nothing was contaminated.

2 / 28 - I followed step-by-step to pace myself when I had too many changes in my supplies and a new infusion pump. First, I

focused on having an awareness of these problems and stopped myself from wishing the insurance hadn't changed and decided

to solve this. I had to get organized; I took the next step to practice all the new stuff - it worked!

2 / 30 - I wish I had the energy to do my hobby. So I tried using the nap tape, that little snooze was refreshing

2 / 30 - Tomorrow I am going to exercise. I will start by walking up the block and back. My goal is walk all the way around the block.

2 / 31 - My emotions rating was a 4 yesterday, so I listened to my favorite CD on the way to the hospital to visit my husband. I was pretty calm by the time I got there. When I got back home, I spent time in my garden.

Date:
Date:___
Date:
Date:

Table 5: Monitoring your emotions and reactions through writing.

\section{Topics During Peer Support}

Encouraged activities outside of IV home-care.

Discussed ways for saving money in day-to-day treatment. Increased understanding of healthcare professionals directions.

Shared common experiences.

Gained emotional support.

Suggestions on how to engage with the healthcare team.

\section{Examples}

Shared experiences on ways to stay engaged, including visiting with friends / family, drawing, taking care of pets, gardening, traveling, etc.

Shared experience on keeping a notebook comparing IV equipment costs.

Suggested using iPad to record medical appointments and hospital discharge to assist with remembering complex instructions given.

Shared similar struggles with fatigue as others described.

Praised a young family caregiver for making time for her young children between infusion cares.

Shared how to approach medical team with questions and provide them information.

Table 6: Topics of peer support discussion and examples of each found in mobile sessions.

for deep breathing and muscle relaxation. The gradually decreasing music tempo induces relaxation by synchronizing with a wake-to-sleep heart rate cadence. Our previous clinical trial showed a recuperative effect (0.45) [65], as did another study (0.67) [66]. A Cochrane review also reports that music enhances healthy sleep [67].

To use this sleep promotion intervention, a nap icon is easily accessible with the music choices on the iPad mini home screen. Families choose their preferred music genre such as classical, country, easy-listening, slow hip-hop, or soft rock. The gradually decreasing music tempo initiates sleep. After 20 minutes of napping, a wake-up alarm sounds because sleeping longer than 20 minutes has been shown to cause grogginess and more difficulty falling asleep at bedtime. Families are taught that naps are not a substitute for a full night's sleep.

Family healthy living activities intervention: Because the demands of managing complex home care often result in family members neglecting their own health, we engage them in basic healthy living activities, namely healthy eating and monitoring recommended sugar and salt intake and daily walk exercise. Participants were instructed to consult with their primary care provider before engaging in these healthy activities [68]. These behaviors, suggested by the $\mathrm{NIH}$, are evidence-based programs and safe even for older adults [69-71]. The goal is to increase families' awareness of the importance of improving a healthy dietary intake and increasing exercise. These activities are reinforced through follow-up automated prompts with persuasive statements sent via iPad mini email accounts [72-74]. Selfmonitoring and prompts have significantly improved healthy eating and are associated with increased exercise $[75,76]$.

Daily self-monitoring and early symptom reporting using the interactive checklist: Using a self-monitoring checklist available $24 / 7$ on the IVhomeCare intervention website (Table 4) patients are encouraged to review their IV catheter homecare routines with their healthcare providers and to discuss any daily care concerns during the mobile group sessions. This checklist has been verified to result in daily self-monitoring and early symptom reporting, which can ward off serious health-related complications such as IV catheter infections [11]. The checklist guides patients to monitor signs and symptoms of infections. It instructs them to adhere to a complex twice daily IV infusion routine including hand washing, recording body temperature, maintaining a clean work area and asepsis during IV care procedures, and assessing the IV catheter site for inflammation and signs of infection. Self-monitoring skills are developed and practiced by patients and reinforced by the healthcare professionals. Problemsolving partnerships with professionals improve daily self-monitoring skills, and peer group discussions provide social support. With practice, patients learn how to weave self-management skills into their daily IVhomeCare routines [77,78].

\section{Results}

\section{Analyses}

There were 126 participants (55 patients and 71 family caregivers) who attended the videoconferencing group sessions $(\mathrm{n}=41)$ via iPad. Participants' average age was $41.87(S D=19.95)$, ranging from 14 to 79 years, and $53 \%(\mathrm{n}=19)$ were male. Of the 126 participants, $70(81.2 \%)$ had experience with IV home-care for between 1 to 5 years.

Our mobile-based intervention was evaluated by patient and family ratings of their use of mobile health care on the iPad tablet [79]. On a scale from 1 to $5(1=$ not helpful and $5=$ very helpful $)$, patients and family caregivers rated the IVhomeCare intervention program, materials, and technical support as helpful (4) [80]. Subjects reported that they enjoyed meeting with professionals who provided information and facilitated discussion with other families in the iPad group sessions $(M=4.69, S D=0.68)$. Sharing their challenges in the iPad group sessions gave them a sense of connection with health professionals and others managing IVhomeCare $(M=4.60, S D=$ 0.69). The peer support was rated as giving them the sense of not being the only one who gets the blues $(M=4.43, S D=0.85)$. Participants 
gained problem-solving skills by hearing effective ways to manage IVhomeCare from others through iPad group discussion $(M=4.60, S D$ $=0.60)$. In addition, almost all participants $(94 \%)$ rated themselves as highly satisfied with the overall interventions and would recommend this type of mobile delivery to others $(M=4.40, S D=1.33)$. Further, Table 6 provides examples from the discussed topics that illustrate how peer support was helpful to families.

All the patients and family members received the IVhomeCare intervention via iPad group sessions free of charge. All participants also indicated that they were willing to pay from $\$ 25$ to $\$ 50$ per iPad group session with multidisciplinary healthcare professionals and other patients and family caregivers, even if insurance would not cover this cost. However, they also felt that the sessions were worth being covered by insurance companies. Both professionals and patients rated these approaches as saving them time and money. Patients also mentioned the convenience of the intervention and in knowing "their health care professional can be in close contact." One disadvantage that professionals described however was the lack of connection between the iPad data collected and electronic medical records. Professionals wished to have a direct connection for storing the photographs taken of patients during their iPad exams and for typing their notes into a patient's legal medical record. It is likely those technical features will be developed in the near future.

\section{Discussion}

As shown in Table 2, there are major advantages to translation of the IVhomeCare interventions for delivery via iPad mini tablets with $4 \mathrm{G}$ access. First, the mobile technology provides easy access to evidence-based online resources with increased ease of use and availability virtually anytime and anyplace that meet patients and family members' needs. This includes access to information and guidance that supports independent self-management for complex IV care. Second, the mobile technology supports group interactions in realtime using secure videoconferencing. This allows patients and families to connect with other patients and families around the country, as well as with healthcare facilitators. There is the added benefit that these iPad based support groups decrease social isolation. And third, rather than gathering at a hospital or clinic, the iPad meetings do not require travel or introduce additional infection risk. Such mobile approaches maximize patient and caregiver confidence in managing complex lifelong daily home IV care.

Families participating in the group discussions receive support and encouragement from other families who have successfully selfmanaged IVhomeCare issues, and they receive information and guidance from healthcare professionals at a distance. During the peer group discussion, patients and family members shared their experiences and offered support to one another (Table 6). One subject who was developmentally disabled was comfortable using the iPad and engaging with health professionals during the audiovisual sessions and openly participated in the group discussion. Yet family indicated she was reluctant to share during in-person doctor visits. In another case where the subject was deaf, a family member typed what was being discussed during the group iPad session so their parent could follow and participate in the group discussion.

The costs for setting up mobile videoconferencing sessions can be offset by saving out-of-pocket travel costs and travel time [81], as well as providing the opportunity for the health professionals to meet with the whole family [82]. Previous research found the average out-of-pocket health care costs for these patients was $\$ 17,000$ annually with travel to local and distant specialists [83]. The cost for the iPad support group sessions is considerably less than the cost for travel to meet individual healthcare providers, a single emergency department visit, or one inpatient hospitalization for catheter-related infection. Immediate examination of IV catheter sites and communication with patients on their health status will lead to early diagnosis and treatment initiation, which in turn will reduce morbidity and mortality in the long term. The current emphasis on preventing and reducing morbidity and mortality rates from catheter-related infections supports the translation of our IVhomeCare intervention.

A significant advantage that patients described was the opportunity for group discussion sessions with other patients and their family members. These sessions allowed them to share their day-to-day issues and the solutions they use for their lifelong required IV infusions, managing the fatigue that is common, and the importance of maintaining a positive outlook. Several patients confirmed that the post appointment iPad group discussion was the first time they had met others with the same illness and the same needs, issues, and challenges for the life sustaining IV treatments. However, one common disadvantage in introducing new healthcare delivery systems is merging the new technology with electronic health records as noted by healthcare professionals.

\section{Conclusion}

Due to the extensive daily care demands and financial hardship of complex IV infusion technology, using a mobile distance connection to 24/7 IVhomeCare web-based information and access to healthcare via the mobile platform iPad, for guiding families to use evidence-based interventions, is important to continue testing. Mobile technology can assist participants to avoid life-threatening infections, monitor emotions and fatigue, keep healthy, and decrease costs such as reduced travel for visiting healthcare providers.

Patients who require daily IV infusions at home must adhere to strict technical procedures for survival. Patients and family members need support in mastering the complex technological skills that are required to avoid life-threatening infections. Family education will be effective if the family members perceive that they are well prepared to manage home care, especially when visits to healthcare providers and specialists are both time-consuming and costly. In this study evidencebased interventions were translated to the mobile environment. This includes the asynchronous educational videoconferencing components.

New technologies are constantly arising, even during the course of this intervention. The "lessons learned" in this study may continue to apply in the mobile environment, even as the specific device improves and continues to advance intervention possibilities in the healthcare arena. The early identification of IV catheter infection and potentially fatal IV sepsis may well encourage the use of mobile technologies. This study adds to the knowledge base for assessing technology delivery of health care on health outcomes and translation of the evidenced-based intervention to homecare practice.

\section{Disclosure}

The project was part of a larger study supported by the National Institute of Biomedical Imaging and Bioengineering (NIBIB) R01 EB015911, C. Smith, Principal Investigator. In addition, this study is partially supported from National Institutes of Health (NIH) U54 RR031295 Trail Blazer Award \#UL1TR000001 to C. Smith from Frontiers: The Heartland Institute for Clinical and Translational Research. The content is solely the responsibility of the authors and 
Citation: Smith CE, Piamjariyakul U, Werkowitch M, Yadrich DM, Thompson N, et al. (2016) A Clinical Trail of Translation of Evidence Based Interventions to Mobile Tablets and IIIness Specific Internet Sites. Sensor Netw Data Commun 5: 138. doi:10.4172/2090-4886.1000138

does not necessarily represent the official views of the National Institute of Biomedical Imaging and Bioengineering or the Frontiers: Heartland Institute.

\section{Acknowledgement}

We are grateful for the recommendations and Telemedicine expertise contributed to this trial by Dr. Ryan Spaulding (Associate Vice Chancellor for Community Engagement, University of Kansas Medical Center). And to ChangMing (Jeremy) Ko, MS MA our Technical Specialist. The authors extend their appreciation to Sally Barhydt (Publication Consultant) for her editorial support and to all patients who participated in this study for their time and use of mobile healthcare interventions.

\section{References}

1. Bozzetti F, Staun M, Van Gossum A (2006) Home Parenteral Nutrition Cambridge: CABI.

2. Winkler MF, Smith CE (2015) The Impact of Long-Term Home Parenteral Nutrition on the Patient and the Family: Achieving Normalcy in Life. J Infus Nurs 38: 290-300.

3. Piamjariyakul U, Yadrich DM, Ross VM, Smith CE, Clements F, et al. (2010) Complex home care: Part 2-family annual income, insurance premium, and out-of-pocket expenses. Nurs Econ 28: 323-329.

4. Smith CE, Piamjariyakul U, Yadrich DM, Ross VM, Gajewski B, et al. (2010) Complex home care: part III-economic impact on family caregiver quality of life and patients' clinical outcomes. Nurs Econ 28: 393-399.

5. Winkler MF, Smith CE (2014) Clinical, social and economic impacts of home parenteral nutrition dependence in short bowel syndrome. J Parenter Enteral Nutr 38: 32S-37S.

6. Winkler MF (2007) American Society of Parenteral and Enteral Nutrition Presidential Address: food for thought: it's more than nutrition. J Parenter Enteral Nutr 31: 334-340.

7. Smith CE, Cha JJ, Kleinbeck SVM, Clements FA, Cook D, et al. (2002) Feasibility of in-home telehealth for conducting nursing research. Clin Nurs Res 11: 220-233.

8. Fitzgerald SA, Yadrich DM, Werkowitch M, Piamjariyakul U, Smith CE (2011) Creating patient and family education websites: Design and content of the home parenteral nutrition family caregivers website. Comput Inform Nurs 29: 637-645.

9. Spaulding R, Smith CE, Nelson EL, Yadrich D, Werkowitch M, et al. (2014) iCare: mHealth Clinic Appointments Using iPad Minis Between Multiple Professionals and Intravenous Dependent Patients in their Homes; ATA Case Study. American Telemedicine Association.

10. Smith CE, Spaulding R, Piamjariyakul U, Werkowitch M, Yadrich DM, et al (2015) mHealth Clinic Appointment PC Tablet: Implementation, Challenges and Solutions. J Mob Technol Med 4: 21-32.

11. Smith CE, Curtas S, Kleinbeck SVM, Werkowitch M, Mosier M, et al. (2003) Clinical trial of interactive and videotaped educational interventions to reduce catheter-related infection, reactive depression, and rehospitalizations for sepsis in patients receiving home parenteral nutrition. J Parenter Enteral Nutr 27: 135-145.

12. Yadrich DM, Fitzgerald SA, Werkowitch M, Smith CE (2012) Creating patient and family education web sites: assuring accessibility and usability standards. Comput Inform Nurs 30: 46-54.

13. Kelly K, Smith CE, Eskenazi L (2007) Technology and family caregiving: Advantages and challenges for delivering education, training, and support Gerontologist 47: 272-273.

14. Smith CE (2007) Testing virtual nurse caring by picture phones and internet with home parenteral nutrition patients. Clin Nutr 2: 43-44.

15. Saqui O, Chang A, McGonigle S, Purdy B, Fairholm L, et al. (2007) Telehealth videoconferencing: improving home parenteral nutrition patient care to rural areas of Ontario, Canada. J Parenter Enteral Nutr 31: 234-239.

16. Smith CE (2007) Testing Virtual Nurse Caring of Picture Phones and Internet with Home Parenteral Nutrition Patients. Clinical Nutrition 2: 43-44.

17. National Alliance for Caregiving (2014) Catalyzing Technology to Support Family Caregiving. Key steps to better support family caregiving through the use of mobile, online, and in-home technologies.
18. Schulz DN, Kremers SP, Vandelanotte C, Van Adrichem MJ, Schneider F, et al. (2014) Effects of a web-based tailored multiple-lifestyle intervention for adults: a two-year randomized controlled trial comparing sequential and simultaneous delivery modes. J Med Internet Res 16: e26.

19. Howard L (2006) Home parenteral nutrition: survival, cost, and quality of life. Gastroenterology 130: S52-59.

20. Smith CE, Curtas S, Kleinbeck SV, Werkowitch M, Mosier M, et al. (2003) Clinical trial of interactive and videotaped educational interventions reduce infection, reactive depression, and rehospitalizations for sepsis in patients on home parenteral nutrition. J Parenter Enteral Nutr 27: 137-145.

21. The Oley Foundation (2013) Tools for living better on home IV and tube feedings: Tips for traveling with Home PEN.

22. Winkler MF, Ross VM, Piamjariyakul U, Gajewski B, Smith CE (2006) Technology dependence in home care: impact on patients and their family caregivers. Nutr Clin Pract 21: 544-556.

23. Smith CE, Leenerts MH, Gajewski BJ (2003) A systematically tested intervention for managing reactive depression. Nurs Res 52: 401-409.

24. West DM (2015) How Mobile Devices are Transforming Healthcare.

25. Gaskamp CD (2004) Quality of life and changes in health insurance in longterm home care. Nurs Econ 22: 135-139.

26. National Alliance for Caregiving (2014) Catalyzing Technology to Suppor Family Caregiving. Key steps to better support family caregiving through the use of mobile, online, and in-home technologies.

27. Holopainen A, Galbiati F, Voutilainen K (2007) Use of Smart Phone Technologies to Offer Easy-to-Use and Cost-Effective Telemedicine Services. First International Conference on the Digital Society, Guadeloupe.

28. Fox S (2014) The social life of health information.

29. Lewis N (2014) Health IT Sees Key Market in Family Caregivers. Healthcare Information Week.

30. Fiordelli M, Diviani N, Schulz PJ (2013) Mapping mHealth research: a decade of evolution. J Med Internet Res 15: e95.

31. Wolbring G, Lashewicz B (2014) Home care technology through an ability expectation lens. J Med Internet Res 16: e155.

32. Spaulding R, Smith CE, Nelson EL, Yadrich D, Werkowitch M, et al. (2014) iCare: Testing iPad Visual Sessions Between Interdisciplinary Professionals and Families Managing Intravenous Dependent Patients in their Homes; ATA Case Study. American Telemedicine Assoication.

33. Lewis N (2014) Health IT Sees Key Market in Family Caregivers. Healthcare Information Week.

34. Metzger LC (2010) Education materials for home nutrition support consumers Nutr Clin Pract 25: 451-470.

35. Smith C (2008) Technology and Web-based support. Am J Nurs 108: 64-68.

36. Fitzgerald SA, Macan Yadrich D, Werkowitch M, Piamjariyakul U, Smith CE (2011) Creating patient and family education web sites: design and content of the home parenteral nutrition family caregivers web site. Comput Inform Nurs 29: $637-645$

37. Winkler MF, Smith CE (2015) The Impact of Long-Term Home Parenteral Nutrition on the Patient and the Family: Achieving Normalcy in Life. J Infus Nurs 38: 290-300.

38. Smith CE (2005) Website algorithms. Gerotechnology 3: 217

39. Winkler MF, Smith CE (2015) The Impact of Long-Term Home Parentera Nutrition on the Patient and the Family: Achieving Normalcy in Life. J Infus Nurs 38: 290-300.

40. Smith CE, Curtas S, Robinson JM (2001) Case study of patients helping patients program. Nutrition 17: 175-176.

41. Fox S (2012) Pew Internet News: Wireless Internet Use, the Internet and the Recession, Mobile technology use. Pew Research Center's Internet and American Life Project.

42. Baker TB, Gustafson DH, Shah D (2014) How can research keep up with eHealth? Ten strategies for increasing the timeliness and usefulness of eHealth research. J Med Internet Res 16: e36.

43. Fitzgerald SA, Macan Yadrich D, Werkowitch M, Piamjariyakul U, Smith CE 
Citation: Smith CE, Piamjariyakul U, Werkowitch M, Yadrich DM, Thompson N, et al. (2016) A Clinical Trail of Translation of Evidence Based Interventions to Mobile Tablets and IIIness Specific Internet Sites. Sensor Netw Data Commun 5: 138. doi:10.4172/2090-4886.1000138

(2011) Creating patient and family education web sites: design and content of the home parenteral nutrition family caregivers web site. Comput Inform Nurs 29: 637-645.

44. Smith CE, Spaulding R, Piamjariyakul U, Werkowitch M, Yadrich DM, et al. (2015) mHealth Clinic Appointment PC Tablet: Implementation, Challenges and Solutions. J Mob Technol Med 4: 21-32.

45. Smith CE, Werkowitch M, Piamjariyakul U, Clements $F$, Schaag $H$, et al (2009) Music Strategies to Improve Health and Fatigue. Music: Composition, Interpretation and Effects. Hauppauge, NOVA, Science Publishers, New York.

46. National Institutes of Health (2014) Turning discovery into health. Clear Communication: A NIH health literacy initiative.

47. Yadrich DM, Fitzgerald SA, Werkowitch M, Smith CE (2012) Creating patient and family education web sites: assuring accessibility and usability standards. Comput Inform Nurs 30: 46-54.

48. HON (2009) Confidentiality, proper attribution, justifiability and validity of the health information provided code. Health on the Net Foundation.

49. Infusion Nurses Society (2011) Infusion nursing standards of practice. J Infusion Nurs 34: S1-S109.

50. Smith CE (2009) Empirically Verified Music-Based Sleep Promotion and Infections Control Interventions for ICU. Intense Times 2009: 72-76.

51. CDC (2013) CDC-Guidelines Hand Hygiene.

52. Mermel LA, Allon M, Bouza E, Craven DE, Flynn P, et al. (2009) Clinical practice guidelines for the diagnosis and management of intravascular catheter-related infection: 2009 Update by the Infectious Diseases Society of America. Clin Infect Dis 49: 1-45.

53. Pihl-Lesnovska K, Hjortswang H, Ek AC, Frisman GH (2010) Patients' perspective of factors influencing quality of life while living with Crohn disease. Gastroenterol Nurs 33: 37-44.

54. Smith CE, Piamjariyakul U, Yadrich DM, Ross VM, Gajewski B, et al. (2010) Complex home care: part III-economic impact on family caregiver quality of life and patients' clinical outcomes. Nurs Econ 28: 393-399.

55. Stiles-Shields C, Keefer L (2015) Web-based interventions for ulcerative colitis and Crohn's disease: systematic review and future directions. Clin Exp Gastroenterol 8: 149-157.

56. Huang VW, Reich KM, Fedorak RN (2014) Distance management of inflammatory bowel disease: systematic review and meta-analysis. World $J$ Gastroenterol 20: 829-842.

57. Smith CE, Leenerts MH, Gajewski BJ (2003) A systematically tested intervention for managing reactive depression. Nurs Res 52: 401-409.

58. Eisdorfer C, Czaja SJ, Loewenstein DA, Rubert MP, Arguelles S, et al. (2003) The effect of a family therapy and technology-based intervention on caregiver depression. Gerontologist 43: 521-531.

59. Houts PS, Nezu AM, Nezu CM, Bucher JA, Lipton A (1994) American College of Physician's Home Care Guide for Cancer: How to Care for Family and Friends at Home. Philadelphia: American College of Physicians.

60. Toseland R, Rivas R (2005) An introduction to group work practice. ( $5^{\text {th }}$ edn) Needham Heights, MA: Allyn and Bacon.

61. Fortinsky KJ, Fournier MR, Benchimol El (2012) Internet and electronic resources for inflammatory bowel disease: a primer for providers and patients. Inflamm Bowel Dis 18: 1156-1163.

62. Roberts J, Brown GB, Streiner D, Gafni A, Pallister R, et al. (1995) Problem solving counseling or phone-call support for outpatients with chronic illness: Effective for whom? Canadian J of Nurs Res 27: 111-137.

63. Smith CE (2009) Empirically Verified Music-Based Sleep Promotion and Infections Control Interventions for ICU. IntenseTimes.
64. Winkler MF, Hagan E, Wetle T, Smith C, Maillet JO et al. (2010) An exploration of quality of life and the experience of living with home parenteral nutrition. $J$ Parenter Enteral Nutr 34: 395-407.

65. Smith CE, Dauz E, Clements F, Werkowitch M, Whitman R (2009) Patient education combined in a music and habit-forming intervention for adherence to continuous positive airway (CPAP) prescribed for sleep apnea. Patient Educ Couns 74: 184-190.

66. Twiss E, Seaver J, McCaffrey R (2006) The effect of music listening on olde adults undergoing cardiovascular surgery. Nurs Crit Care 11: 224-231.

67. Cepeda MS, Carr DB, Lau J, Alvarez H (2006) Music for pain relief. Cochrane Database Syst Rev- CD004843.

68. CDC (2008) Center for Disease Control \& Prevention and the KimberlyClark Corporation. Assuring Healthy Caregivers, A Public Health Approach to Translating Research into Practice: The RE-AIM Framework. Neenah, WI: Kimberly-Clark Corporation.

69. Sternfeld B, Block C, Quesenberry CP Jr, Block TJ, Husson G, et al. (2009) Improving diet and physical activity with ALIVE: a worksite randomized trial. Am J Prev Med 36: 475-483.

70. National Institute on Aging (2009) Exercise \& Physical Activity and Healthy Eating. National Council on the Aging Evidence-based Health Promotion Series.

71. NIA (2015) New National Institute on Aging Website: Go4Life.

72. Schulz DN, Kremers SP, Vandelanotte C, Van Adrichem MJ, Schneider F, et al. (2014) Effects of a web-based tailored multiple-lifestyle intervention for adults: A two-year randomized controlled trial comparing sequential and simultaneous delivery modes. J Med Internet Res 16: e26.

73. Fogg BJ (2003) Persuasive Technology: Using Computers to Change What We Think and Do. Morgan Kaufmann Publishers, San Francisco.

74. Guerini M, Stock O, Zancanaro M (2007) A taxonomy of strategies for multimodal persuasive message generation. Applied Artificial Intelligence 21 99-136.

75. Helsel DL, Jakicic JM, Otto AD (2007) Comparison of techniques for selfmonitoring eating and exercise behaviors on weight loss in a correspondencebased intervention. J Am Diet Assoc 107: 1807-1810.

76. Normand MP (2008) Increasing physical activity through self-monitoring, goal setting, and feedback. Behavioral Interventions 23: 227-236.

77. American Society for Parenteral and Enteral Nutrition (2004) Safe practices for PN.

78. Green BB, Anderson ML, Ralston JD, Catz S, Fishman PA, et al. (2011) Patient ability and willingness to participate in a web-based intervention to improve hypertension control. J Med Internet Res 13: e1

79. Smith CE (2010) Internet Nursing Care: Patient Teaching in the Internet Age. NOVA Science. Hauppauge, NOVA Science Publishers, NY.

80. Houck S, Kilo C, Scott J (2013) Family Practice Management. Improving Patient Care Group Visits 101

81. Piamjariyakul U, Smith CE, Ross VM, Yadrich D, Williams AR, et al. (2010) Part II: HPN Family Income, Insurance Premiums and Put-of-Pocket Expenses. Nurs Econ 28: 255-264.

82. Kim H, Spaulding R, Werkowitch M, Yadrich D, Piamjariyakul U, et al (2014) Costs of multidisciplinary parenteral nutrition care provided at a distance via mobile tablets. J Parenter Enteral Nutr 38: 50S-7S.

83. Piamjariyakul U, Ross VM, Yadrich DM, Williams AR, Howard L, et al. (2010) Complex home care: Part I-Utilization and costs to families for health care services each year. Nurs Econ 28: 255-263. 